\title{
Bedrock detection using 2D electrical resistivity imaging along the Peikang River, central Taiwan
}

\author{
Han-Lun Hsu ${ }^{a}$, Brian J. Yanites ${ }^{b}$, Chien-chih Chen ${ }^{\mathrm{a}, *}$, Yue-Gau Chen ${ }^{\mathrm{c}}$ \\ a Institute of Geophysics, National Central University, Jhongli, 32001 Taiwan, ROC \\ b Department of Geological Sciences, University of Colorado, 2200 Colorado Ave., Boulder, CO 80309, USA \\ ' Department of Geosciences, National Taiwan University, Taipei, 10617 Taiwan, ROC
}

\section{A R T I C L E I N F O}

\section{Article history:}

Received 24 November 2008

Received in revised form 18 August 2009

Accepted 19 August 2009

Available online $\mathrm{xxxx}$

\section{Keywords:}

Landscape evolution

Sediment transport

Sediment budgets

2D electrical resistivity imaging method

Laplacian edge detection

\begin{abstract}
A B S T R A C T
We use the two-dimensional (2D) electrical resistivity imaging (ERI) method to detect the contact between sediment and bedrock in a modern fluvial system. We performed eight 2D electrical resistivity surveys along the Peikang River in Kuohsing area, central Taiwan, with a pole-pole array of $1-\mathrm{m}$ electrode spacing to produce a spatial resolution of about $1 \mathrm{~m}$. The resistivity data were inverted into subsurface electrical structures using the least-squares inversion techniques. Then, the contact between the bedrock and sediment was found by using an image processing technique called Laplacian edge detection (LED), which represents an objective approach in interpreting various geophysical images. Numerical modeling demonstrates that isoresistivity lines are not in good agreement with the hypothetical interfaces between the bedrock and sediment, but the zero-lines of the Laplacian operation are strikingly accurate. Our results indicate a well-defined boundary in the resistivity structure that can be used to estimate the quantity of sediments covering bedrock, thus highlighting the utility of this technique in studies of landscape evolution, sediment transport, and sediment budgets.
\end{abstract}

(C) 2009 Published by Elsevier B.V.

\section{Introduction}

The erosion of bedrock is an important mechanism that shapes topographic features and links climatic and tectonic processes. Previous research has shown that sediment in fluvial systems plays a dual role as it can both protect the bedrock from erosion and also abrade it (Sklar and Dietrich, 2001, 2004). The quantity of sediments covering bedrock is an important control on river incision (Korup and Montgomery, 2008). To fully understand how the transport and distribution of sediment affects the incision process, we need to evaluate the quantity of sediment covering bedrock. A reliable estimation of the contact between the sediments and the bedrock is thus crucial for exploring the volume of sediment in river bottoms. By using nondestructive geophysical investigation techniques, such as the two-dimensional (2D) electrical resistivity imaging (ERI) method, we can quantify the magnitude and variability of sediment covering bedrock faster, cheaper, and over a broader area than drilling a well or digging a trench (Hauck et al., 2003; Crook et al., 2008). The 2D ERI method has been a powerful technique to investigate shallow subsurface electrical structures in various environments (Cheng, 2000; Yang et al., 2002; Hauck et al., 2003; Sass, 2007; Cheng et al., 2008; Crook et al., 2008).

\footnotetext{
* Corresponding author. Tel.: +8863422 7151 65653; fax: +8863422 2044 E-mail address: chencc@earth.ncu.edu.tw (C. Chen).
}

The 2D electrical resistivity imaging method, because of its high resolution, is commonly used in measuring the electrical structure of shallow subsurface within several tens to hundred meters deep. A 2D electrical resistivity imaging survey is produced by injecting current into the ground through two current electrodes and measuring the resulting voltage difference at two potential electrodes. This process is repeated for many current/potential electrode configurations to produce a pseudosection of apparent resistivity. The resultant data are then processed using a 2D inversion. Variations in the underlying sediment or rock units indicated by different electrical resistivities can then be observed as strong gradients in resistivity. Although the subsurface resistivity distribution could then be interpreted and mapped by eye, we will show that this subjective method should be done with caution because of the diffusive nature of the electrical field. This paper aims at defining a better location of the electrical interface between a high-resistivity layer and a low-resistivity layer, like the bedrock-sediment contact, by applying the Laplacian edge detection (LED) method (Marr and Hildreth, 1980; Vafidis et al., 2005) to an electrical resistivity image. Thus, we can find the contrasts at where resistivity changing from two main resistivity layers in the resistivity image. We will present our model verification of the LED method and also its application to detect the bedrock/sediment interface along the Peikang River, central Taiwan (Fig. 1).

The Peikang River drains the western flank of the Backbone Range, cuts through the Hsueshan Range across strike, and continues on through the western foothills (Fig. 1). The continuous succession of 
(A)
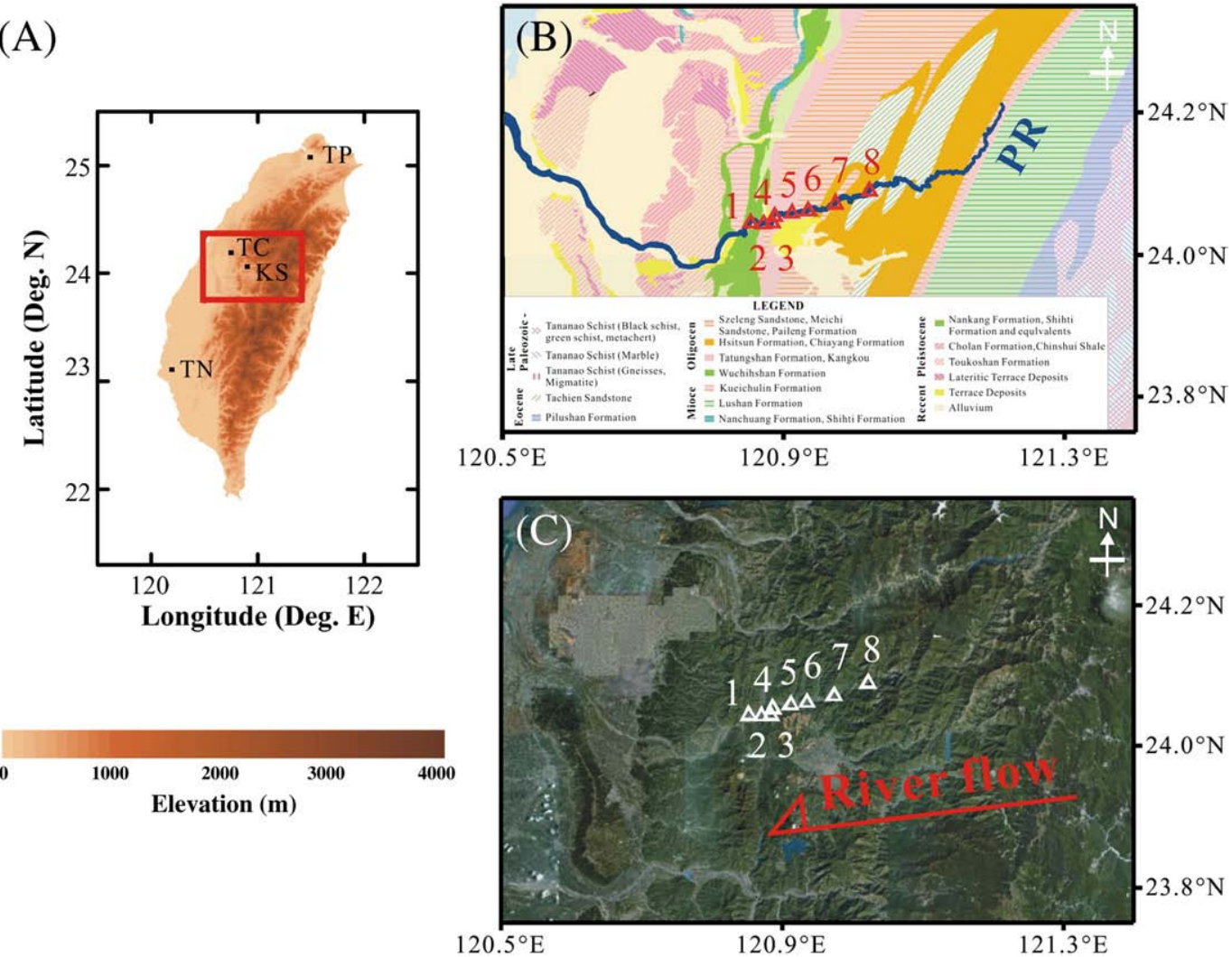

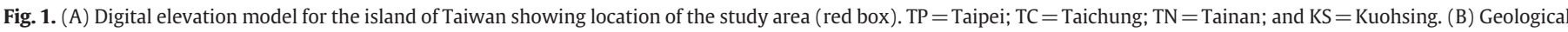

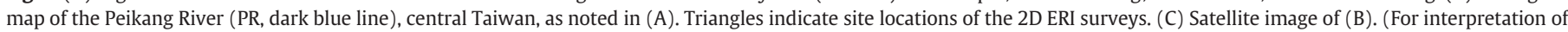
the references to colour in this figure legend, the reader is referred to the web version of this article.)

Oligocene to Miocene strata in the Kuohsing area, central Taiwan, consists of the following formations in ascending order (Mao et al., 2002): Paileng Formation, Shuichangliu Formation, Shihszeku Formation, Tanliaoti Formation, Shihmentsun Formation, Changhukeng Formation, Talu Formation, Kuanyinshan Sandstone, and Kueichulin Formation. The river in the Kuohsing area is incising Miocene metasedimentary rocks over the Holocene (Yanites et al., 2008). Data from a local gauging station suggest annual flood discharges on the order of hundreds of $\mathrm{m}^{3} / \mathrm{s}$ with a maximum daily value of $1800 \mathrm{~m}^{3} / \mathrm{s}$ in 2004. Most importantly, this particular reach of the Peikang River is relatively unaltered by human disturbance. There are no major dams or other such structures throughout. Thus, we are seeing the sediment cover genuinely produced by natural processes.

\section{2D electrical resistivity imaging (ERI) method and data collection}

Traditionally, the direct-current (DC) electrical survey is used to determine the subsurface resistivity distribution by measuring the electrical potential difference between a pair of potential electrodes ( $\mathrm{M}$ and $\mathrm{N}$ in Fig. 2) on the ground surface with a current applied through a pair of current electrodes (A and B in Fig. 2) (Keller and Frischknecht, 1966; Telford et al., 1990). The apparent resistivity $\rho_{a}$ in ohm-meter $(\Omega-\mathrm{m})$ is then computed from Ohm's law:

$\rho_{a}=2 \pi n \Delta v / I$

where $n$ is distance in meters between the electrodes; $\Delta v$ is the measured potential difference in $\mathrm{mV}$; and $I$ is the applied electric current in $\mathrm{mA}$.

Recent developments in DC technology allow automatic measurements, by switching the current and potential electrodes between a series of equally spaced electrodes laid out along a profile (Fig. 2B-D) (e.g., Yang et al., 2002; Hauck et al., 2003). This allows a dense sampling of subsurface resistivity variation at shallow depth within a short amount of time. We use the standard pole-pole array to map the near-surface electrical structures. This array is configured by setting one current $(\mathrm{A})$ and one potential $(\mathrm{N})$ electrode to be placed at a distance along the profile of "infinity." In practice, this distance is often over 10 times the distance between the starting and ending electrodes used in the profile ( $B_{1}$ and $M_{\text {end }}^{\text {end }}$ in Fig. 2). This allows their influence to be ignored with respect to the close electrodes $\mathrm{B}$ and $\mathrm{M}$ (Keller and Frischknecht, 1966; Telford et al., 1990; Cheng et al., 2008). The ERI data are then collected by using a series of the equally spaced electrodes ( $\mathrm{B}_{i}$ and $\mathrm{M}_{i}^{j}$ in Fig. 2B). The automatic survey is starting at one end of the profile, using the first central electrode as the current electrode $B$. The electrical potential is then measured sequentially along the profile using each following central electrode as the potential electrode M (Fig. 2B). Then, the current electrode is automatically switched to the second electrode along the profile and the potential measurement is conducted over the subsequent electrodes (Fig. 2C). The automatic switches are carried on from one end to the other until the survey along the profile is finished (Fig. 2D). This produces a subsurface map of the "apparent" resistivity distribution.

The apparent resistivity distribution of the subsurface structure is then inverted using the commercial RES2DINV ${ }^{\circledR}$ software to estimate the true resistivity structure. The algorithm uses a 2D smoothnessconstrained, least-squares inversion with a Jacobian matrix calculation for the first iteration and then employs a quasi-Newtonian technique to reduce numerical calculations (Loke and Barker, 1995, 1996). The inversion is stopped once the difference of the root mean square (RMS) error between the current and previous iterations is 


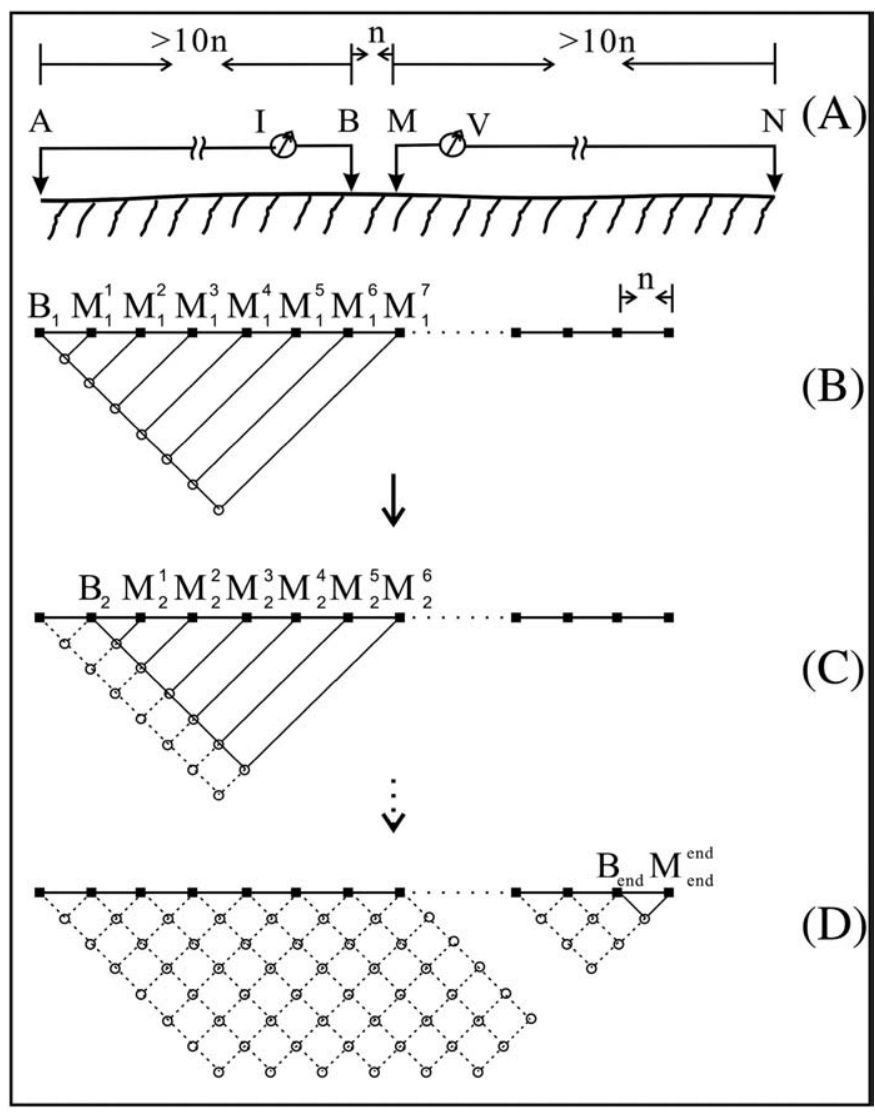

Fig. 2. Electrode configuration of the pole-pole array used in this study. (A) A sketch about the relationship of the current $(A-B)$ and potential $(M-N)$ electrodes. For the pole-pole array, the electrodes $\mathrm{A}$ and $\mathrm{N}$ should be located far away the central electrodes B and $\mathrm{M}$ at $\sim 10$ times the distance between B and M. (B)-(D) Automatic measurement of the pole-pole array. An automatic ERI survey begins at one end of the central group of $\mathrm{B}_{i}-\mathrm{M}_{i}^{i}$ electrodes and works by switching sequentially the electrodes to the other end of the central electrode array. For details please refer to the text.

$<0.1 \%$. The inverted data produce the $2 \mathrm{D}$ resistivity distribution map, which can then be used for extracting information about the contact between sediment and bedrock.

The 2D ERI data in this study were collected at eight sites along the Peikang River in the Kuohsing area, central Taiwan (Fig. 1). At all sites, surveys were conducted mostly perpendicular to the river channel and located on the dry river beds, below bankfull flow, in a river dominated by summertime typhoon generated floods (Fig. 3). Then, to check for the reproducibility in the data, we conducted surveys parallel to the river channel at two sites, i.e., sites 2 and 7. We collected the high-resolution 2D ERI data by using an electrode spacing of $1 \mathrm{~m}$, giving a vertical resolution of about $1 \mathrm{~m}$. The infinity electrodes are located at distances of 10 times the profile length away from the center of each ERI profile. That is, for a 50-m-long ERI profile, the infinity electrodes were $500 \mathrm{~m}$ away; and for an ERI profile with $200 \mathrm{~m}$, the infinity electrodes were $2 \mathrm{~km}$ away. Total length of the 2D ERI profile at each site depends on the width of the terrace in the river, which ranges from 47 to $191 \mathrm{~m}$ (Table 1 ).

\section{Laplacian edge detection (LED) and its verification}

There are many ways to objectively detect edges in an image (Marr and Hildreth, 1980; Vafidis et al., 2005). Two widespread categories of edge detection are the gradient- and Laplacian-based techniques. The difference between these techniques can be easily visualized with a 1D example as shown in Fig. 4. The gradient approach detects the edges of an image by finding the maximum of the first derivatives of

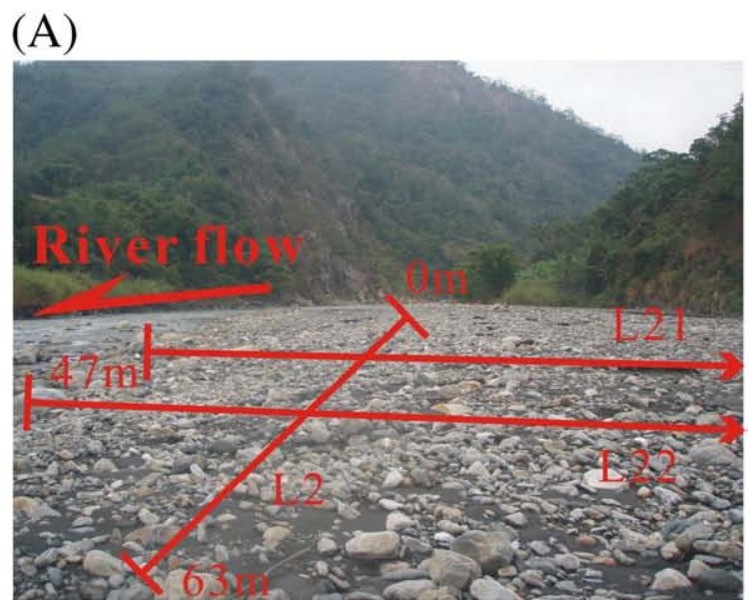

(B)

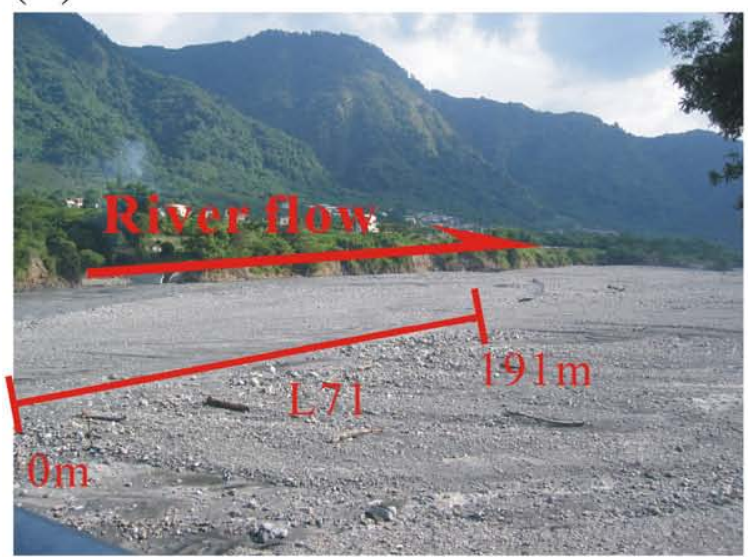

(C)

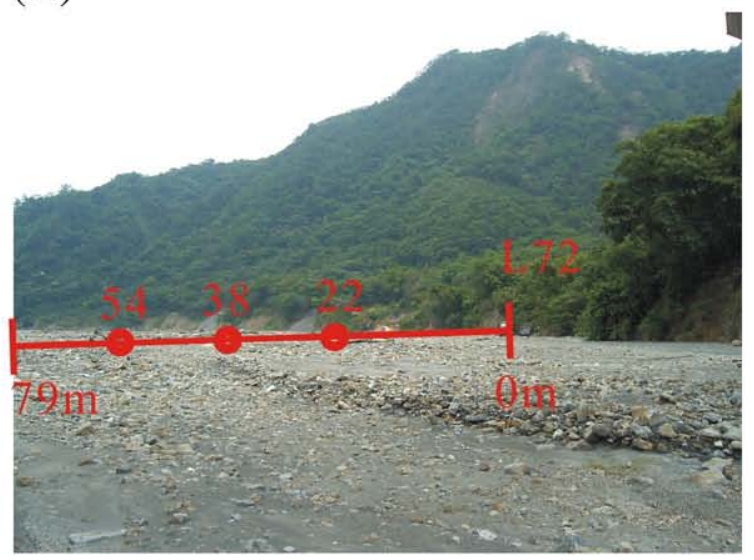

Fig. 3. Photographs of (A) site 2, (B) and (C) site 7. The solid lines mark the ERI profiles. The circles in $(\mathrm{C})$ indicate the locations of the boreholes in Fig. 8D. As shown in these photographs, the ERI profiles were located on the dry river beds.

an image (Fig. 4B). The Laplacian method searches for values of zero in the second derivatives of the image (Fig. 4C). For a 2D image, where $Z$ is the quantity of interest (e.g., resistivity) and $x$ and $y$ are coordinates, the Laplacian operator is defined as

$$
\nabla^{2} Z(x, y)=\frac{\partial^{2} Z}{\partial x^{2}}+\frac{\partial^{2} Z}{\partial y^{2}}
$$

By calculating the Laplacian, we find where the Laplacian is zero (hereinafter we call it the Laplacian zero-line) it corresponds to the 
Table 1

Information about eleven ERI lines located at eight sites (Fig. 1) along the Peikang River central Taiwan.

\begin{tabular}{lcll}
\hline ERI site/line \# & $\begin{array}{l}\text { Length of ERI } \\
\text { profile }(\mathrm{m})\end{array}$ & $\begin{array}{l}\text { Average and range of } \\
\text { estimated depth of } \\
\text { sediment-bedrock } \\
\text { contact }(\mathrm{m})\end{array}$ & $\begin{array}{l}\text { Perpendicular or } \\
\text { parallel to the direction } \\
\text { of river flow }\end{array}$ \\
\hline Site 1/L1 & 79 & $4.0 / 2.4-6.9$ & Perpendicular \\
Site 2/L21 & 47 & $3.0 / 1.4-5.1$ & Perpendicular \\
Site 2/L22 & 47 & $3.0 / 1.3-5.0$ & Perpendicular \\
Site 2/L2 & 63 & $2.0 / 1.4-2.8$ & Parallel \\
Site 3/L3 & 95 & $5.2 / 1.1-9.9$ & Perpendicular \\
Site 4/L4 & 63 & $2.2 / 1.3-4.2$ & Perpendicular \\
Site 5/L5 & 47 & $2.6 / 1.5-3.5$ & Perpendicular \\
Site 6/L6 & 79 & $5.2 / 1.8-11.3$ & Perpendicular \\
Site 7/L71 & 191 & $11.8 / 6.2-15.3$ & Parallel \\
Site 7/L72 & 79 & $12.0 / 9.1-14.5$ & Perpendicular \\
Site 8/L8 & 79 & $8.3 / 1.6-13.4$ & Perpendicular \\
\hline
\end{tabular}

abrupt change (i.e., the edge) in the original data. This is appealing in electrical techniques because, as electric current flows through two materials with different electrical resistivities, the electrical charges are piled up at the electrical boundary. That is, electrons are discharged on one side of the boundary between two electrical media and recharged on the other side, producing abrupt changes in the inverted data. Thus, the Laplacian operator can, in a mathematical sense, provide a measure of discharge or recharge flux across a surface. We therefore expect that the LED method can be extremely valuable to the analysis of an electrical resistivity image.

To demonstrate the LED method, we modeled an arbitrary twolayered (high-resistance sediment over low-resistance bedrock) system with a saw-toothed interface (Fig. 5A). In addition, we also modeled anomalous high-resistivity blocks (e.g., gravel or sand lenses) embedded within the cover layer (Fig. 5B). The resistivity of the upper layer is set as $300 \Omega \mathrm{m}$ and the lower half-space layer $10 \Omega \mathrm{m}$. For the second model in Fig. 5B, the high-resistivity anomalous blocks have a resistivity of $1000 \Omega \mathrm{m}$ and dimensions of $3 \mathrm{~m}$ in width and $2 \mathrm{~m}$ in thickness, comparable to our observations. Fig. $5 \mathrm{~A}$ and $\mathrm{B}$ plot the inverted electrical images obtained from the forwarded-modeled resistivity data of the two models above. The gray solid lines show the hypothetical interface between the upper and lower layers (Fig. 5A), as well as the locations of the anomalous blocks (Fig. 5B). The black solid lines fairly coincident with the hypothetical interfaces are the Laplacian zero-lines obtained from the LED method. We also draw the isoresistivity lines of $300 \Omega \mathrm{m}$ (the black dashed line above the interface) and $10 \Omega \mathrm{m}$ (the black dashed line below the interface). While those isoresistivity lines are not in good agreement with the hypothetical interfaces, the zero-lines of the Laplacian operation are strikingly accurate. We have also tested the LED method for an electrical model with a low-resistivity layer over a highresistivity layer (Fig. 5C). Consequently, the LED method can work as well to reveal the hypothetical boundary between electrical media.

Another concern associated with the fluvial system is the effect on the LED method of groundwater saturation. For the fluvial system in the dry season, the water-saturated fluvial sediment with relatively low resistivity is supposed to be beneath the unsaturated sediment. Without groundwater filling in the pore space, the upper dry unsaturated sediment is expected to take on high resistivity. We thus developed another three-layered model (Fig. 6) with a relatively high-resistivity layer ( $700 \Omega \mathrm{m}$ ) on the top within a depth of $1.5 \mathrm{~m}$. As shown in Fig. 6, the Laplacian zero-lines (black solid lines) together with large magnitude gradients (purple solid lines) can fit very well to the boundary (gray solid lines) between two main layers in the bottom. The dry unsaturated layer at the shallow depth looks like it is having little effect on the ability to reveal the bedrock-sediment contact of the LED method. The influence of groundwater table could thus be ignored in the analysis of field ERI data.
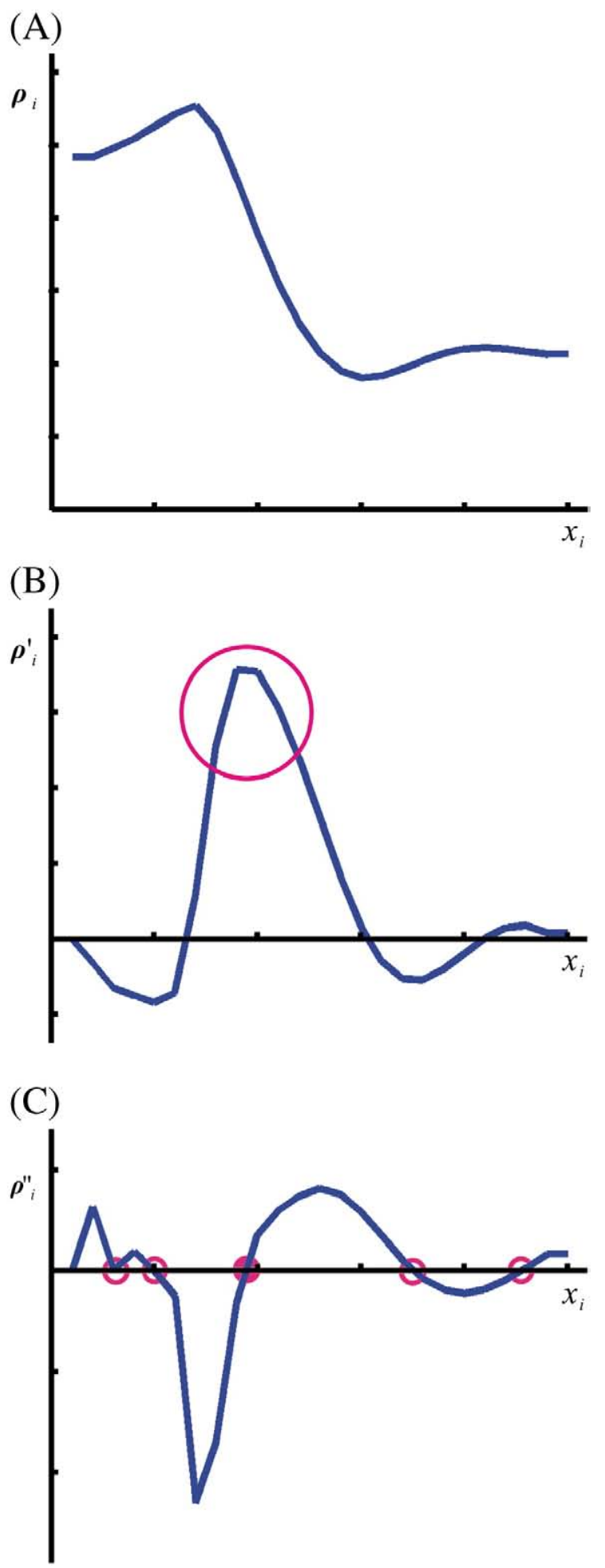

Fig. 4. One-dimensional example illustrating the LED concept: (A) original data. (B) The first derivative, gradient, of (A). Circle shows the areas with large gradient values indicating the possibly broad zone for the electrical boundary. (C) The second derivative, Laplacian, of (A). Circles show the locations with the zero Laplacian. One of the circles (solid one) can fairly locate the electrical boundary.

The above examples suggest that, when applying an external electrical current, the electric recharging/discharging process that occurs across the boundaries between electrical materials could be 
(A)

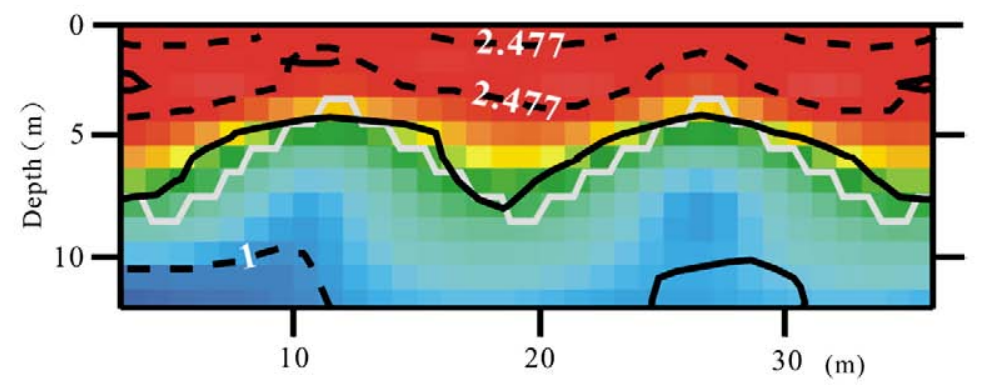

(B)

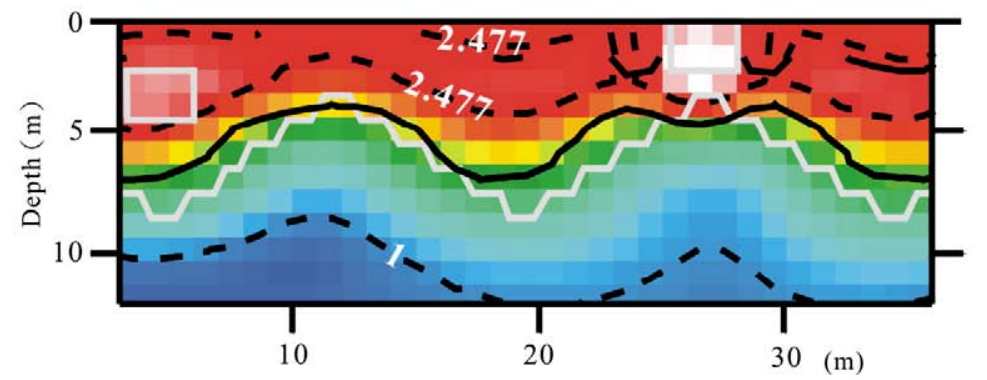

(C)

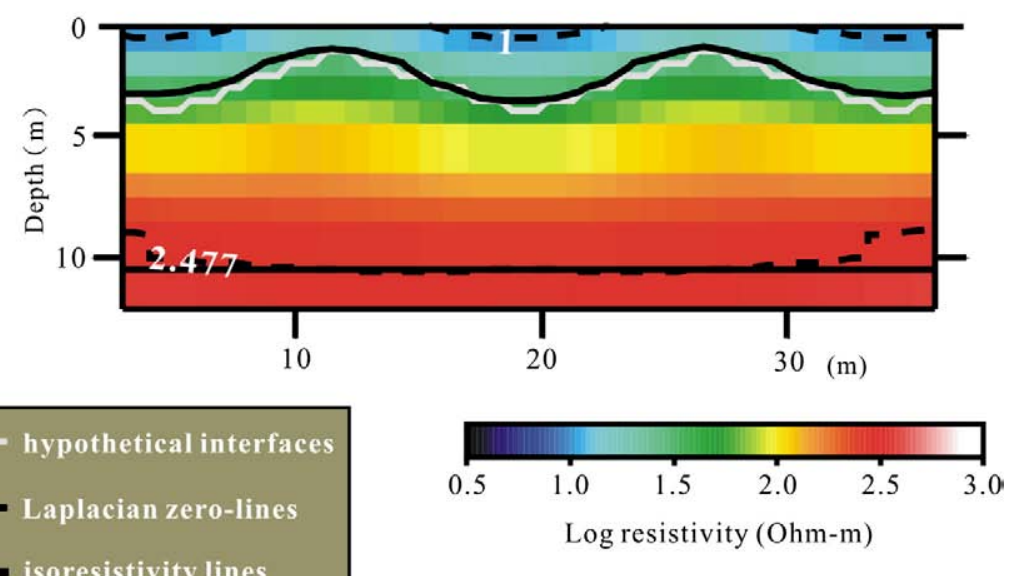

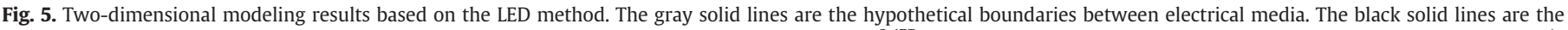

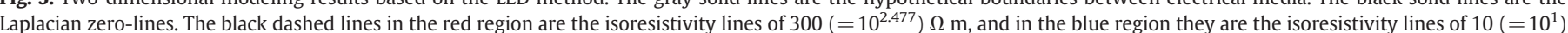

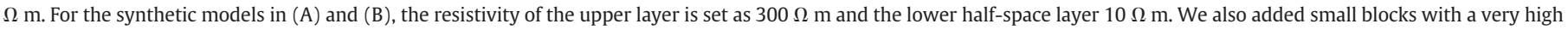

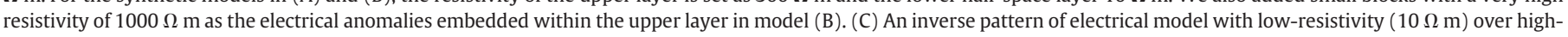
resistivity (300 $\Omega \mathrm{m}$ ) layers. (For interpretation of the references to colour in this figure legend, the reader is referred to the web version of this article.)

characterized by the transition zone in an electrical image. We should note that we have chosen those Laplacian zero-lines with larger (top $20 \%$ ) gradients as the estimated boundaries (solid circle in Fig. 4C), instead of those Laplacian zero-lines with smaller gradients (open circles in Fig. 4C). We did not merely consider the transition zone (orange to green areas in Figs. 5 and 6) as the electrical boundary because of the wide depth range of that zone. The drawback of the LED method is that it also shows some local Laplacian zero-lines around the shallow anomalous blocks as shown in Fig. 5B. Theoretically speaking, those small-scale zero-lines represent the real boundaries between the high-resistivity anomalies and the host matrix. Practically speaking, they represent noise induced by those shallow anomalous bodies that has nothing to do with the bedrock-sediment contact we are targeting. Therefore, special attention is required if such noise structures are present in the interpreted electrical images. For a better estimation of the bedrock-sediment contact, we suggest ignoring the small-scale distorted Laplacian zero-lines not associated with large magnitude gradients in the resistivity values.

\section{Field example of ERI and LED: the Peikang River, central Taiwan}

Shown in Fig. 7 are raw (upper panels in Fig. 7A-C) and inverted (middle panels in Fig. 7A-C) pseudosections for the ERI surveys at sites 1,8 , and 7 along the Peikang River, together with the corresponding best-fit electrical models (lower panels in Fig. 7A-C). Three sections of best-fit electrical models at site 2 are also plotted in Fig. 7D. A similar pattern of subsurface resistivity distributions that depicts a high-resistivity zone above a low-resistivity layer could be found in all of the ERI profiles. The sediment cover has a high resistance because the fluvial deposits produce a relatively high porosity covering the bedrock. The resistivity of the small apertures of pore spaces between these deposits is usually of lower conductance than the consolidated bedrock. This produces the distinct changes in the resistivity distributions, indicating the contact between unconsolidated sediments and consolidated bedrock. Thus, we expect to see the transition in the resistivity distribution changing from an upper resistive covering layer to a lower conductive underlying layer. 

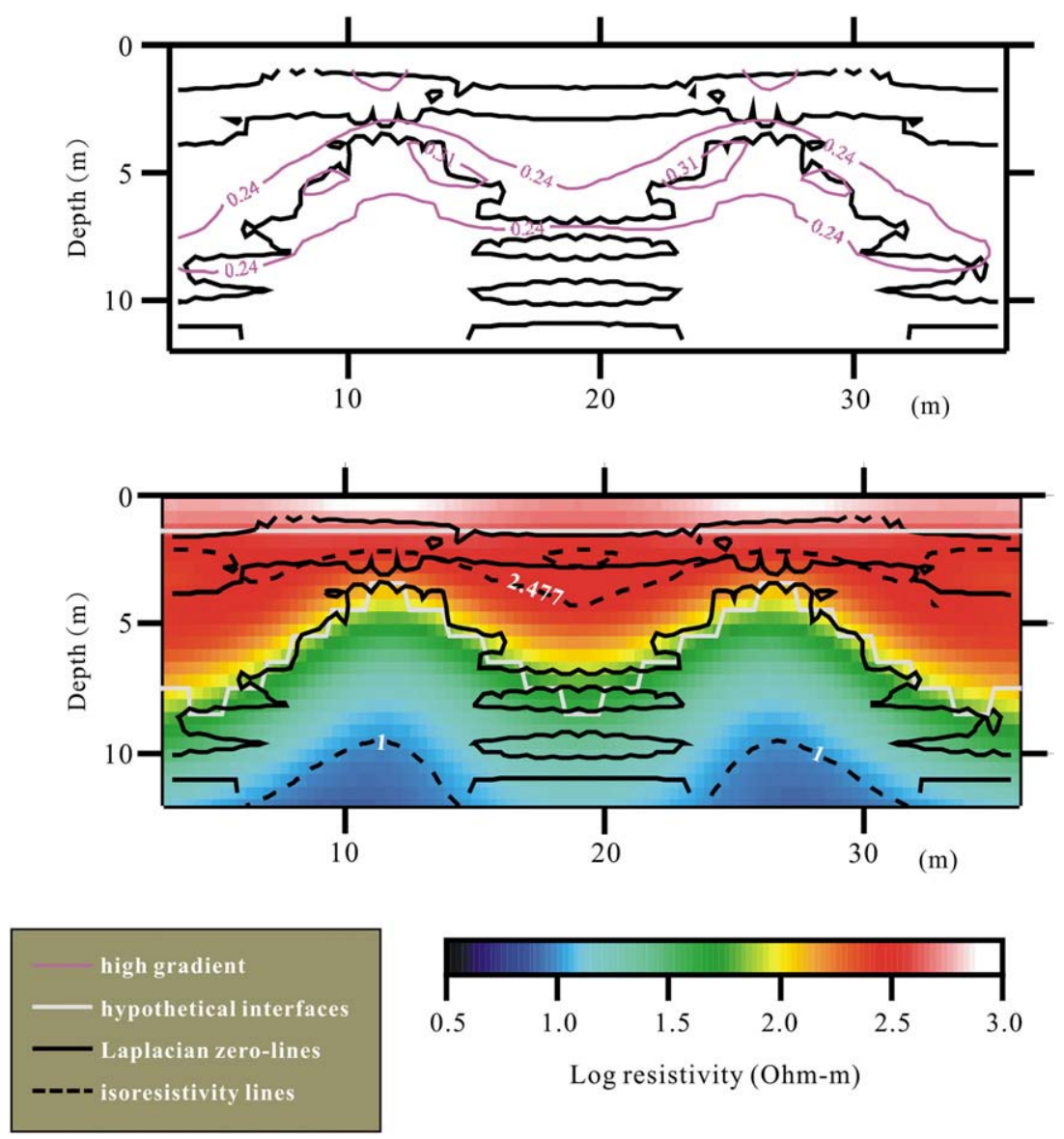

Log resistivity (Ohm-m)

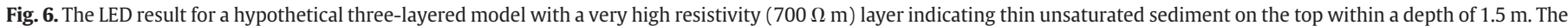

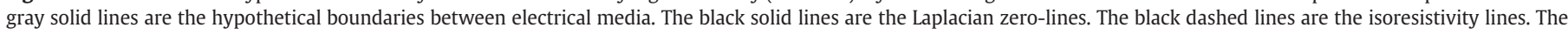

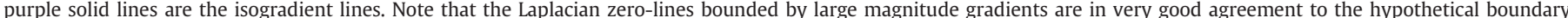

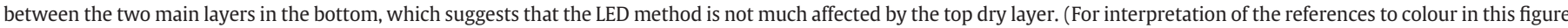
legend, the reader is referred to the web version of this article.)

By applying the LED technique, we then estimate the contacts between the fluvial sediments and underlying bedrock from the inverted resistivity distribution maps. As examples, we show the contact obtained by LED at sites 1,7 , and 8 (Fig. 8). After taking the logarithm of the resistivity data and reimaging the inverted structures, we find that the resistivity distribution could be divided into three general parts: the top layer (red) with high resistivity of about $300 \Omega \mathrm{m}$, the bottom layer (green or blue) with low resistivity of about $30 \Omega \mathrm{m}$, and a transition layer between these end members. We could subjectively define the thin transition layer as the contact between the upper resistive sediments and the lower conductive bedrock; however, based on our simple model demonstrated above, we could also objectively define the contacts as the Laplacian zerolines (white lines in Fig. 8) with large magnitude gradients (blue lines in Fig. 8). The modeling results shown in Section 3 suggest that the Laplacian zero-line can define the contact better than choosing an isoresistivity line as the contact. Therefore, following the LED analysis, we have in Fig. 8 drawn our estimated bedrock-sediment contact (red lines) for each ERI profile.

Digging the trenches/boreholes in some areas is sometimes difficult (e.g., the conservation area for water resources), and is usually more expansive than the nondestructive geophysical techniques. However, after getting some extra budget and complicated official approval, we were allowed to dig some boreholes (Fig. 3C), which constitutes a very important independent validation of the sediment thickness. Although only three boreholes were dug at site 7 because of a limited budget, they provide a valuable check on the ERI and LED results mentioned above. As shown in Fig. 8D, our estimation based on the ERI-LED analysis could be fairly close to the real location of the sediment-bedrock contact.

Yet another way of verification could be based on the establishment of a reliable statistical analysis. Fig. 9 shows the resistivity distribution for all electrical images acquired along the Peikang River. At the high-resistivity end, those resistivities show a well-defined lognormal distribution, i.e., the Gaussian distribution of the logarithm of resistivity data (red curve in Fig. 9). Because of the symmetry of the normal distribution in logarithmic resistivity, we can easily find an approximate log-normal distribution with the logarithmic mean of $2.452(\sim 300 \Omega \mathrm{m})$ and the standard deviation of 0.215 to fit the data at the high-resistivity end. A heavy tail in the low-resistivity end can also be seen in the resistivity distribution. Probably, the electrical resistivity of sediments around the whole study area could be considered as the random variable because of the log-normal distribution of grain size of fluvial sediments (Kodama, 1994; Rice and Church, 1996). Note that the resistivity of fluvial sediment is basically dominated by two factors: porosity and water saturation of pore spaces (Archie, 1942). Therefore, the normal bell shape in the high-resistivity end suggests the resistivity distribution of covering sediments, while the skew to the low-resistivity end indicates the gradual change in the electrical property of the rock as a consequence of their lithological property. We thus expect that the contact between the sediments and bedrock should be located near the margin of the 
(A)

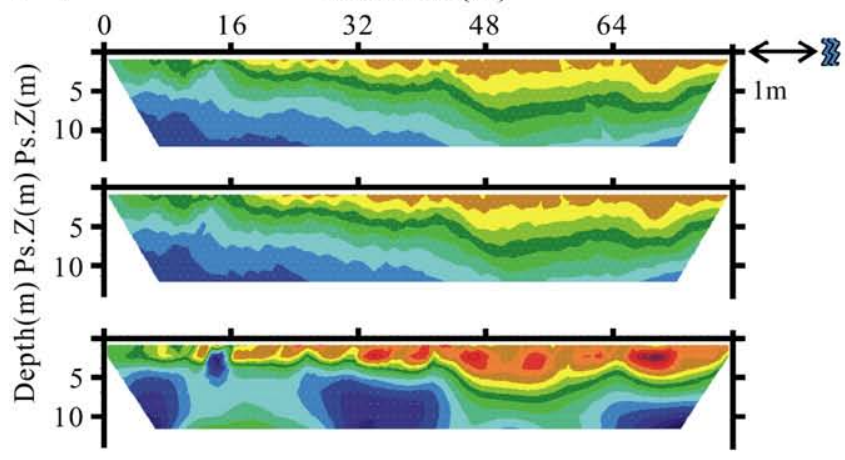

(B)

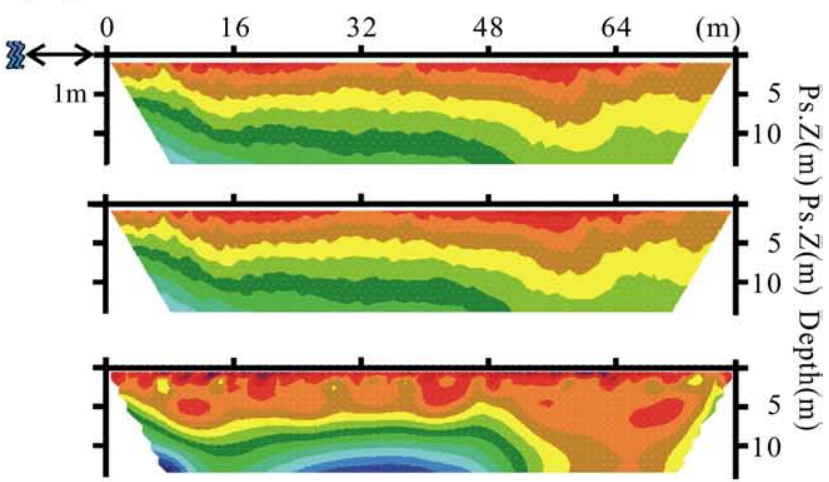

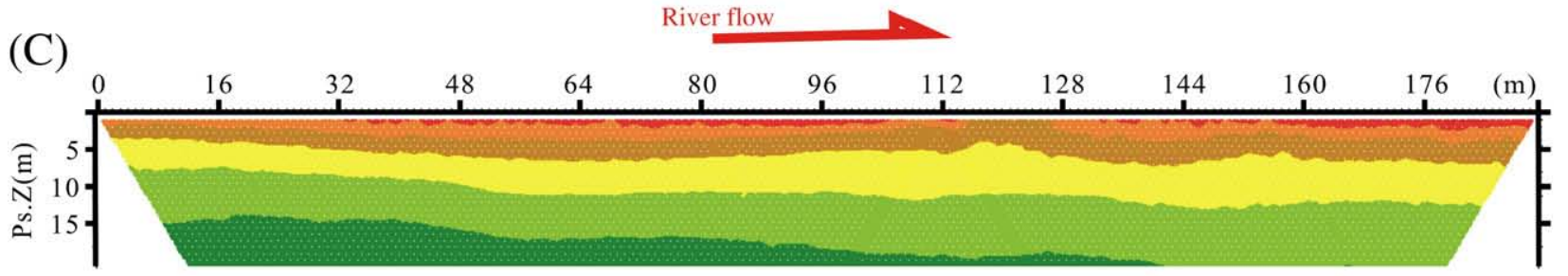
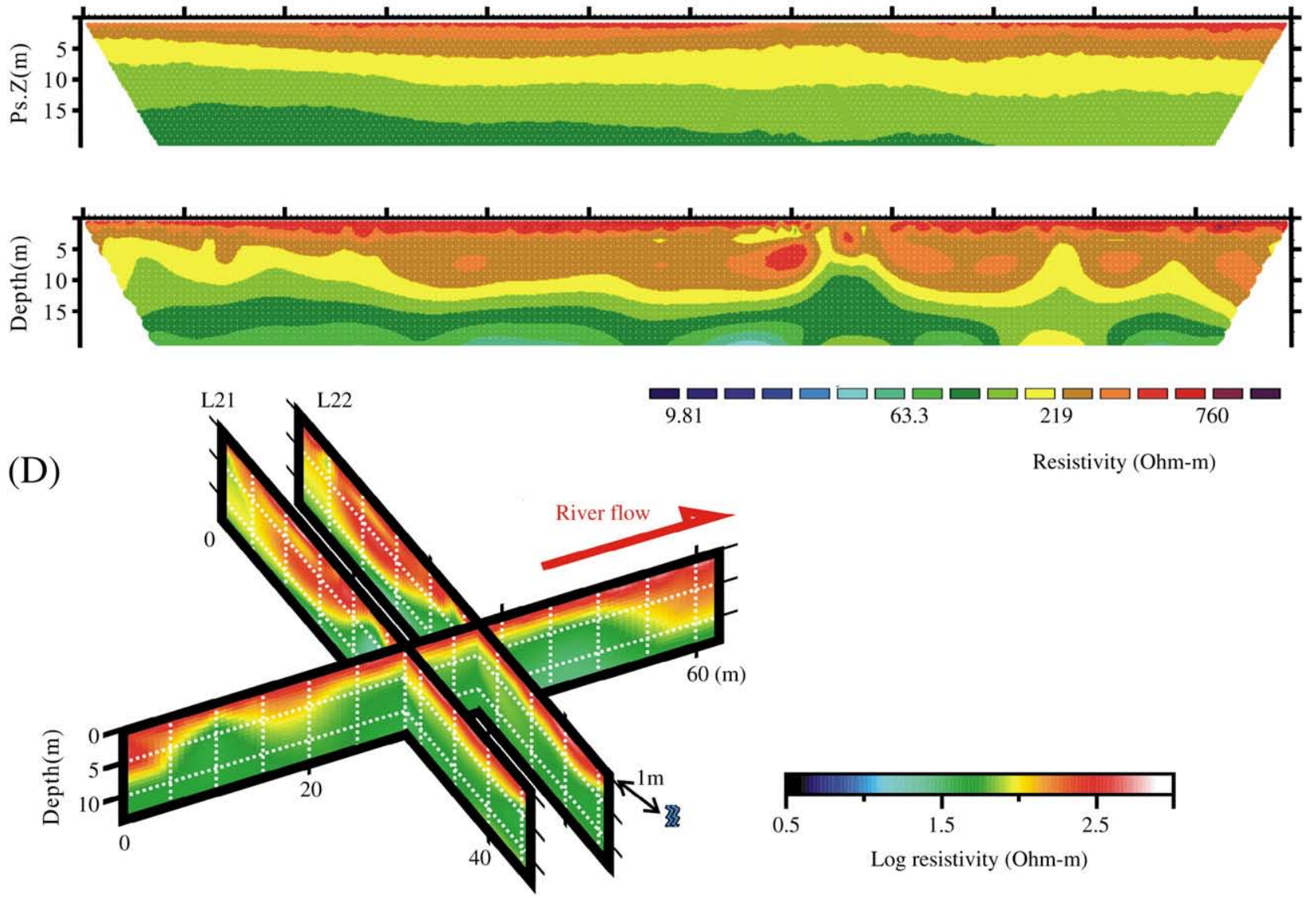

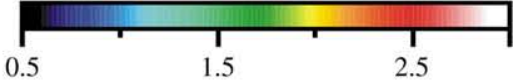

Log resistivity (Ohm-m)

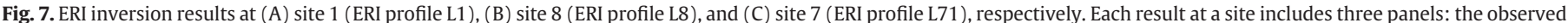

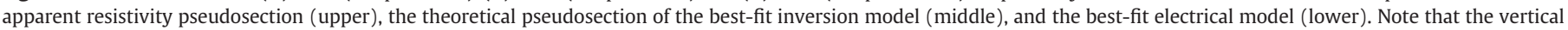

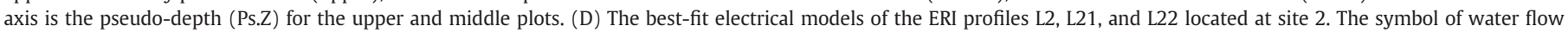
indicates the relative location to each ERI profile of the river channel.

high-resistivity Gaussian bell shape. As shown in Fig. 9, the white cross denotes the range of resistivities of those areas where the Laplacian are zero for the electrical profiles. The horizontal elongation indicates one standard deviation for the resistivity values of those where Laplacian is zero. Such a result of statistical verification suggests that the LED method can give a fairly consistent, reliable definition of the boundary between the fluvial sediments and bedrock from the resistivity image. 
(A)

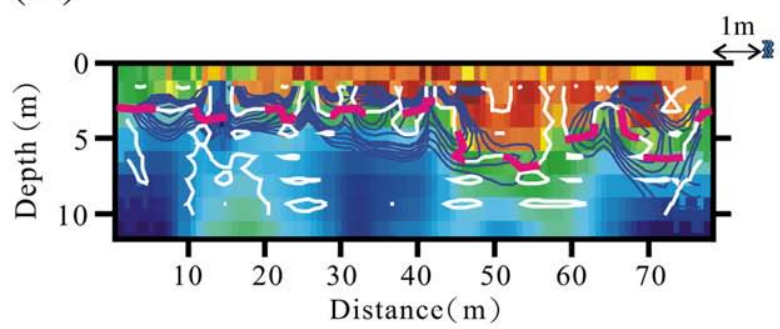

(B)

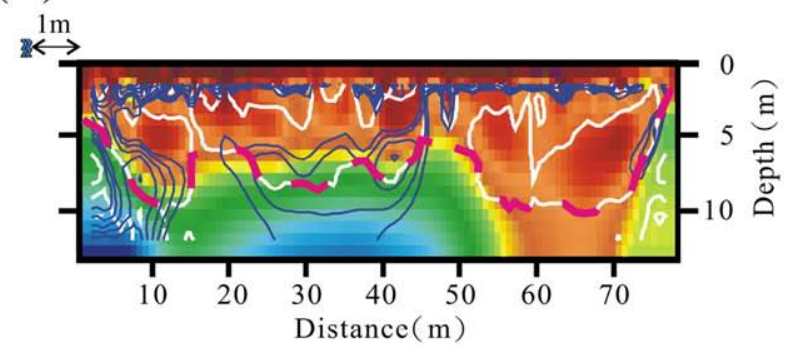

(C)

River flow

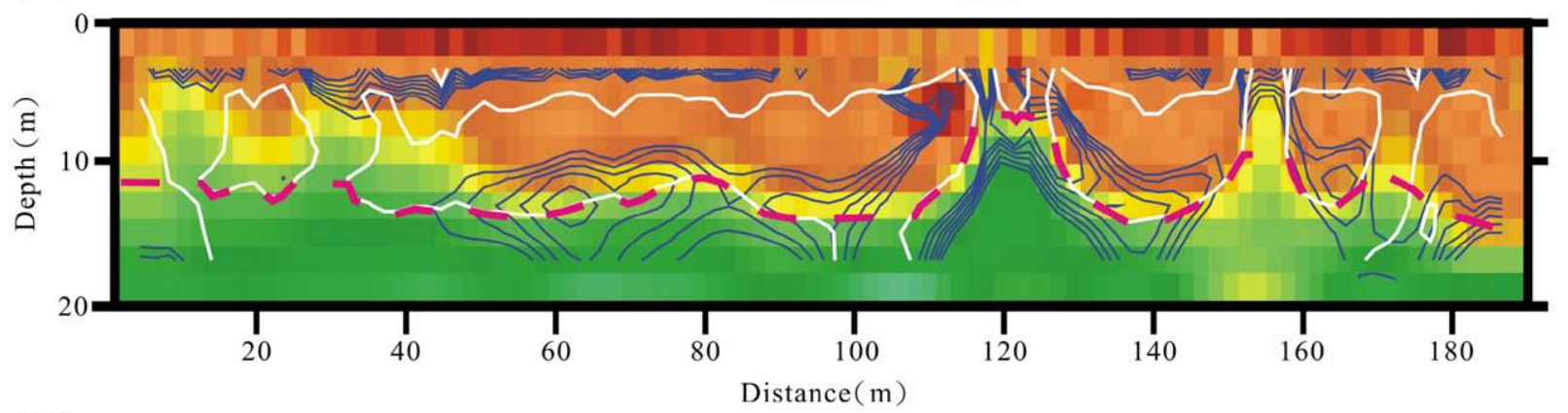

(D)
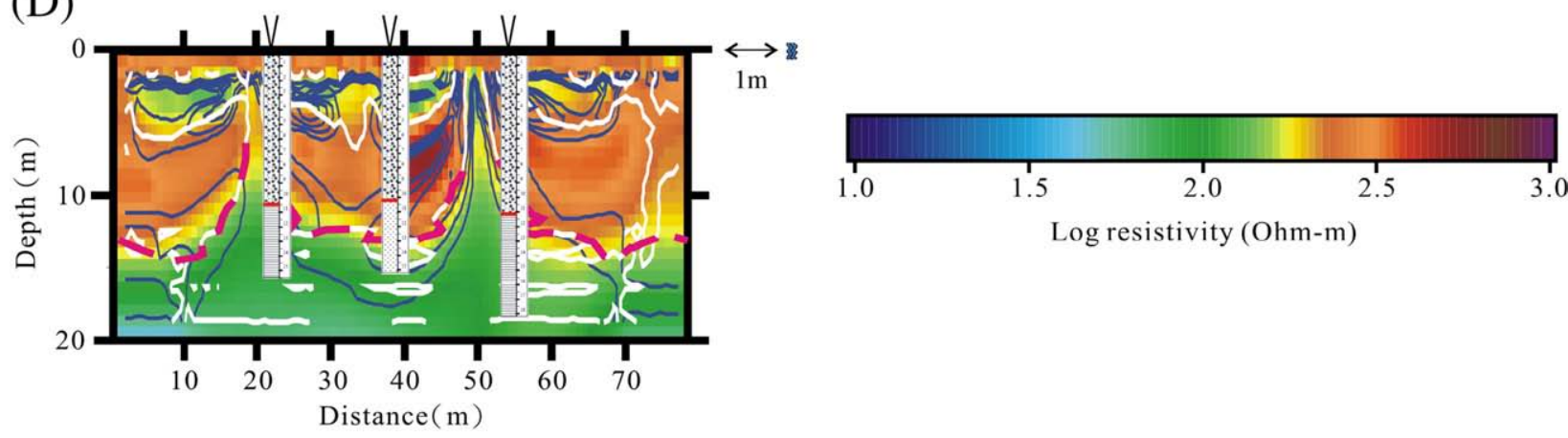

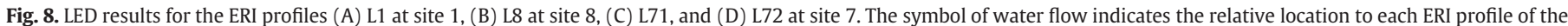

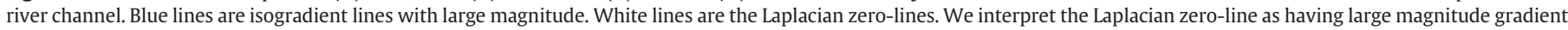

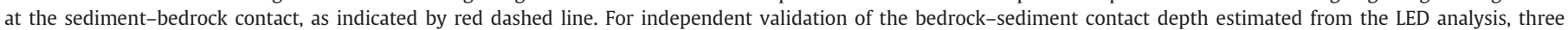

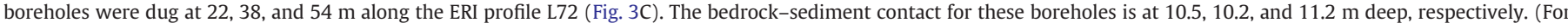
interpretation of the references to colour in this figure legend, the reader is referred to the web version of this article.)

Over the whole study area we can thus estimate the depth of sediment-bedrock contact, which ranges from several to ten meters deep. Table 1 summarizes the length of the ERI profile and the average and range of the depth of sediment-bedrock contact at each site. Accordingly, we took the mean cross-sectional area of sediments from the surveys orientated perpendicular to the river flow direction and then multiplied it by $\sim 30,000 \mathrm{~m}$, i.e., the length of the study reach. We can thus estimate that roughly 12 million $\mathrm{m}^{3}$ of sediment is stored in the modern floodplain above the bedrock of the Peikang River.

\section{Conclusion}

In this study, the 2D ERI method was used to detect the boundary of sediments and bedrock along the Peikang River, central Taiwan. As shown in Fig. 7D, comparison between one river-parallel and two river-perpendicular profiles at site 2 suggests that the electrical models obtained in this study are very much reproducible and in good agreement with the resistivity pattern. We find a consistent distribution in all the 2D ERI profiles (Fig. 7), where a shallow highresistivity zone (interpreted to be fluvial sediment) covers a lowresistivity zone (interpreted to be bedrock). Apparently, resistivity of the sediment follows a log-normal distribution with an average of about $300 \Omega \mathrm{m}$. The broad distribution of resistivity in these sediments is likely influenced by randomness associated with grain size, pore space, and level of water saturation.

We used the LED method to locate the boundaries in the 2D electrical resistivity images. The utility of the LED method was demonstrated by numerical modeling of a hypothetical two-layered structure (Fig. 5), which revealed that the Laplacian zero-line is coincident with the hypothetical boundary while the selection as the boundary of the isoresistivity lines misses the contact by many meters. Aided by the LED method, this study found a good estimation of the contact between sediments and bedrock along the Peikang River, which is useful for understanding the influence of fluvial sediment cover on incision process (Yanites et al., 2008). Statistical analysis of the resistivity distributions (Fig. 9) and borehole data (Fig. 8D) suggest that the LED method gives reliable estimates of the electrical boundary between the sediment and bedrock. We have estimated that roughly 12 million $\mathrm{m}^{3}$ of sediment is stored in the modern floodplain above the bedrock of the Peikang River. Data such as this is necessary to close a sediment budget and calculate residence times in a fluvial system (Malmon et al., 2003). Our methodology 


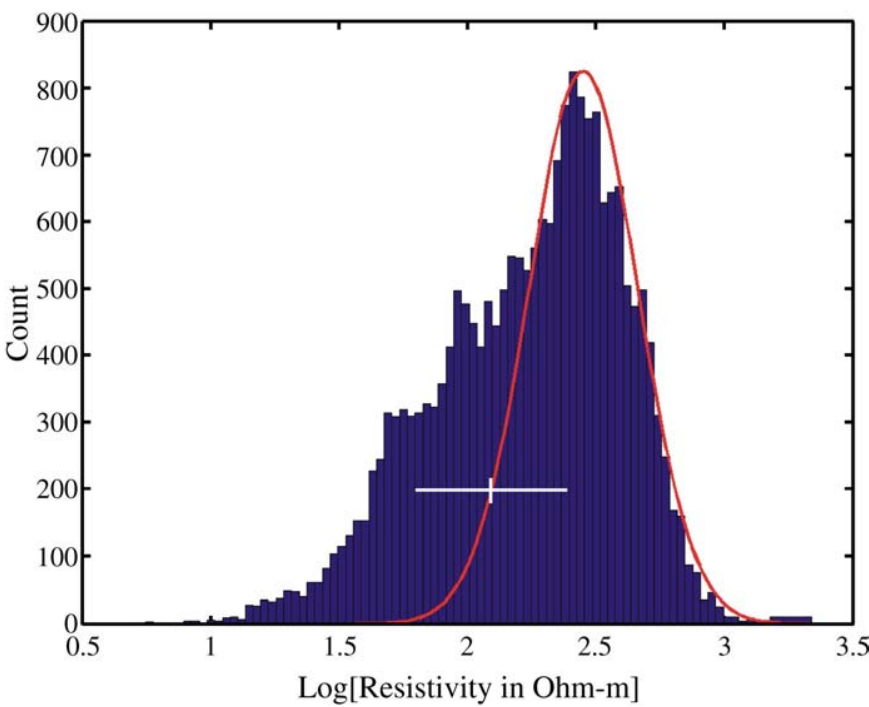

Fig. 9. Histogram of log-resistivity from all measured ERI profiles along the Peikang River. The red curve is an approximate log-normal distribution with the mean of 2.452 and the standard deviation of 0.215 , indicating the resistivity distribution of fluvial sediments. The white cross marks the range of resistivity values at the likely boundaries between the sediment and bedrock estimated from the LED method. (For interpretation of the references to colour in this figure legend, the reader is referred to the web version of this article.)

presented in this paper therefore offers an exciting new technique to study sediment systems in bedrock landscapes.

\section{Acknowledgements}

CCC is grateful for research support from the National Science Council, ROC (NSC 97-2116-M-008-009; NSC 98-2119-M-008-009), and the Department of Earth Sciences at National Central University (ROC). Funding to BJY was provided by an NDSEG fellowship and NSF grant EAR-0510971 and OISE-0611725. The authors deeply thank four anonymous reviewers for their fruitful discussions and suggestions to the early manuscript. Reviewers' suggestions about the verification of the proposed ERI-LED method has led to a push of the second phase, borehole digging in 2009 , of this study that turns out to be an important improvement to the manuscript.

\section{References}

Archie, G.E., 1942. The electrical resistivity log as an aid in determining some reservoir characteristics. Trans. AIME 146, 54-62.

Cheng, P.H., 2000. Imaging the subsurface structure of the northern tip of the 1999 ChiChi earthquake fault in central Taiwan using the electric resistivity method. Terr. Atmos. Ocean. Sci. 11, 721-734.

Cheng, P.H., Ger, Y.I., Lee, S.L., 2008. An electric resistivity study of the Chelungpu fault in the Taichung area, Taiwan. Terr. Atmos. Ocean. Sci. 19, 241-255.

Crook, N., Binley, A., Knight, R., Robinson, D.A., Zarnetske, J., Haggerty, R., 2008. Electrical resistivity imaging of the architecture of substream sediments. Water Resour. Res. 44, W00D13. doi:10.1029/2008WR006968.

Hauck, C., Muhll, D.V., Maurer, H., 2003. Using DC resistivity tomography to detect and characterize mountain permafrost. Geophys. Prospect. 51, 273-284.

Keller, G.V., Frischknecht, F.C., 1966. Electrical Methods in Geophysical Prospecting. Pergamon Press Inc., New York, USA.

Kodama, Y., 1994. Downstream changes in the lithology and grain size of fluvial gravels, the Watarase River, Japan: evidence of the role of abrasion in downstream fining. J. Sediment. Res. 64, 68-75.

Korup, O., Montgomery, D.R., 2008. Tibetan plateau river incision inhibited by glacial stabilization of the Tsangpo gorge. Nature 455, 786-789.

Loke, M.H., Barker, R.D., 1995. Least-squares deconvolution of apparent resistivity pseudosections. Geophysics 60, 1682-1690.

Loke, M.H., Barker, R.D., 1996. Rapid least-squares inversion of apparent resistivity pseudosections by a quasi-Newton method. Geophys. Prospect. 44, 131-152.

Malmon, D.V., Dunne, T., Reneau, S.L., 2003. Stochastic theory of particle trajectories through alluvial valley floors. J. Geol 111, 525-542.

Mao, S., Huang, C.Y., Lei, Z., 2002. Late Oligocene to early Miocene dinoflagellate cysts from the Kuohsing area, central Taiwan. Rev. Palaeobot. Palynol. 122, 77-98.

Marr, D., Hildreth, E., 1980. Theory of edge detection. Proc. R. Soc. Lond., B 207, 187-217.

Rice, S., Church, M., 1996. Bed material texture in low order streams on the Queen Charlotte Islands, British Columbia. Earth Surf. Processes Landf. 21, 1-18.

Sass, O., 2007. Bedrock detection and talus thickness assessment in the European Alps using geophysical methods. J. Appl. Geophys. 62, 254-269.

Sklar, L.S., Dietrich, W.E., 2001. Sediment and rock strength controls on river incision into bedrock. Geology 29, 1087-1090.

Sklar, L.S., Dietrich, W.E., 2004. A mechanistic model for river incision into bedrock by saltating bed load. Water Resour. Res. 40, W06301.

Telford, W.M., Geldart, L.P., Sheriff, R.E., 1990. Applied Geophysics, 2nd ed. Cambridge University Press, Cambridge, UK.

Vafidis, A., Economou, N., Ganiatsos, Y., Manakou, M., Poulioudis, G., Sourlas, G., Vrontaki, E., Sarris, A., Guy, M., Kalpaxis, Th., 2005. Integrated geophysical studies at ancient Itanos (Greece). J. Archaeol. Sci. 32, 1023-1036.

Yang, C.H., Chang, P.H., You, J.I., Tsai, L.L., 2002. Significant resistivity changes in the fault zone associated with the 1999 Chi-Chi earthquake, west-central Taiwan. Tectonophysics 350, 299-313.

Yanites, B.J., Tucker, G.E., Hsu, H., Chen, C., Chen, Y., Mueller, K.J., Wilcox, T., 2008. Variability in Hillslope Sediment Flux Modulates Bedrock Channel Incision Rates: Evidence from the Peikang River, Central Taiwan. Fall Meeting 2008. American Geophysical Union. Abstract \# H54D-06. 